\title{
Repeated transsphenoidal pituitary surgery (TS) via the endoscopic technique: a good therapeutic option for recurrent or persistent Cushing's disease (CD)
}

\author{
M. A. E. M. Wagenmakers*, R. T. Netea-Maier*, E. J. van Lindertt, H. J. L. M. Timmers*, J. A. Grotenhuist \\ and A. R. M. M. Hermus*
}

Pituitary Centre Nijmegen, ${ }^{\star}$ Department of Endocrinology and $\dagger$ Department of Neurosurgery, Radboud University Nijmegen Medical Centre, Geert Grooteplein 8, 6500 HB, Nijmegen, the Netherlands

\section{Summary}

Background No data on results of repeated transsphenoidal surgery via the endoscopic technique for patients with persistent or recurrent Cushing's disease are available.

Design and patients We retrospectively evaluated the remission rates and complications of repeated transsphenoidal surgery via the endoscopic technique in 14 patients with persistent $(N=6)$ or recurrent $(N=8)$ Cushing's disease treated in our centre between 1999 and 2007.

Main outcomes Remission was defined as the disappearance of symptoms of hypercortisolism with basal plasma cortisol level $\leq 50 \mathrm{nmol} / \mathrm{l} 24-48 \mathrm{~h}$ after glucocorticoid withdrawal and/or suppression of plasma cortisol level $\leq 50 \mathrm{nmol} / \mathrm{l}$ after $1 \mathrm{mg}$ dexamethasone overnight within the first 3 months after transsphenoidal surgery.

Results With repeated endoscopic transsphenoidal surgery a remission rate of 10/14 (71\%) was achieved. No patient had a relapse during a median follow-up of 24 months. Cerebrospinal fluid leakage was the most frequent complication (6 patients) and 11 patients required hormonal substitution after surgery. The success of repeated transsphenoidal surgery could not be predicted by visualization of an adenoma on MRI before first or second surgery, histopathological confirmation of an ACTH secreting adenoma after first or second surgery, treatment with cortisol lowering agents before first or second surgery, the operation technique used during the first surgery, persistent $v s$. recurrent disease after the first surgery, age, gender and interval between the two surgeries.

Conclusion Repeated transsphenoidal surgery via the endoscopic technique is a good treatment option for selected patients with recurrent or persistent Cushing's disease following primary pituitary surgery.

\footnotetext{
Correspondence: Margreet Wagenmakers, Department of Endocrinology (471), PO Box 9101, 6500 HB Nijmegen, the Netherlands.

Tel.: +31243614599; Fax: +31243618809;

E-mail: m.vegt-wagenmakers@endo.umcn.nl
}

(Received 16 April 2008; returned for revision 3 May 2008; finally revised 13 June 2008; accepted 23 June 2008)

\section{Introduction}

Cushing's disease $(\mathrm{CD})$ is a potentially life threatening condition that requires aggressive treatment. ${ }^{1,2}$ At present transsphenoidal pituitary surgery (TS) is the primary treatment of choice. Remission rates vary from $50 \%$ to $90 \%$. However, CD persists in the remaining patients, and $5-25 \%$ of the patients who are initially in remission develop a recurrence. $^{3-8}$ Treatment options for persistent or recurrent CD include radiation therapy, bilateral adrenalectomy, medical therapy and repeated TS. Thus far, no consensus exists on which therapy is preferable. $^{5,9,10}$

Pituitary radiotherapy has been used to treat persistent or recurrent $\mathrm{CD}$ for several decades. Remission rates after conventional fractionated radiation therapy range from $56 \%$ to $84 \% .{ }^{5,9}$ However, its usefulness is limited by the delay between therapy and disease control and the 50-100\% incidence of hypopituitarism several years after treatment. Additional complications include radiation necrosis, cerebral vasculopathy, damage to surrounding structures and the development of radiation-induced neoplasms. Stereotactic radiosurgery, which was introduced more recently, may lead to faster normalization of hormone levels with a lower complication risk than conventional radiotherapy, but long-term follow-up is needed to determine its real value. $^{5,9,11,12}$

Bilateral adrenalectomy has a very high success rate of reversing hypercortisolism, ranging from $88 \%$ to $100 \%$. Traditionally, open procedures of adrenalectomy were associated with considerable morbidity and mortality. ${ }^{13,14}$ Nowadays the minimally invasive laparoscopic approach is preferred, which has reduced perioperative morbidity significantly. ${ }^{9,15}$ However, adrenalectomized patients require lifelong glucocorticoid and mineralocorticoid replacement. The major concern is the development of Nelson's syndrome in $15-46 \%$ of the patients. ${ }^{5,16,17}$

Medical therapy in CD mostly serves an adjunctive role after unsuccessful TS. At present only steroidogenesis inhibitors have been proven effective. Furthermore, discontinuation of medical treatment 
Table 1. Clinical characteristics per patient: first and second transsphenoidal pituitary surgery (1999-2007)

\begin{tabular}{|c|c|c|c|c|c|c|c|c|c|c|c|c|c|}
\hline \multirow{3}{*}{$\begin{array}{l}\text { Patient number, } \\
\text { Gender, Age (years) }\end{array}$} & \multicolumn{4}{|c|}{ First surgery } & \multirow{3}{*}{$\begin{array}{l}\text { 1st-2nd } \\
\text { surgery } \\
\text { (months) }\end{array}$} & \multicolumn{8}{|c|}{ Second surgery } \\
\hline & \multirow[b]{2}{*}{ MRI } & \multirow[b]{2}{*}{ Technique } & \multirow[b]{2}{*}{ Histology } & \multirow[b]{2}{*}{ Result } & & \multirow[b]{2}{*}{ CLA } & \multirow[b]{2}{*}{ MRI } & \multirow[b]{2}{*}{ Year } & \multirow[b]{2}{*}{ Technique } & \multirow[b]{2}{*}{ Histology } & \multicolumn{2}{|c|}{ Cortisol (nmol/l) } & \multirow[b]{2}{*}{ Result } \\
\hline & & & & & & & & & & & Basal & After dex & \\
\hline $1, f, 36$ & $<10^{*}$ & $\mathrm{TE}$ & + & $\mathrm{R}$ & 131 & - & $<10$ & 1999 & Endo TS & + & $0 \cdot 50$ & $0 \cdot 02$ & $\mathrm{R}$ \\
\hline $2, \mathrm{f}, 45$ & - & Endo TS & - & $\mathrm{F}$ & 2 & M & - & 2001 & Endo TS & - & $0 \cdot 05$ & $0 \cdot 02$ & $\mathrm{R}$ \\
\hline $3, f, 36$ & - & Endo TS & - & $\mathrm{F}$ & 3 & - & - & 2002 & Endo TS & - & 0.55 & $0 \cdot 21$ & $\mathrm{~F}$ \\
\hline $4, \mathrm{~m}, 30$ & - & Endo TS & - & $\mathrm{R}$ & 11 & M & $<10$ & 2002 & Endo TS & - & 0.02 & $0 \cdot 05$ & $\mathrm{R}$ \\
\hline $5, \mathrm{~m}, 41$ & $<10$ & TS & + & $\mathrm{R}$ & 98 & $\mathrm{~K}$ & $<10$, in & 2005 & Endo TS & NT & $0 \cdot 38$ & - & $\mathrm{F}$ \\
\hline $6, f, 30$ & $<10$ & Endo TS & - & $\mathrm{F}$ & 5 & K & $<10$ & 2005 & Endo TS & + & 0.57 & $0 \cdot 25$ & $\mathrm{~F}$ \\
\hline $7, \mathrm{~m}, 46$ & $<10$ & TS & + & $\mathrm{F}$ & 185 & $\mathrm{~K}$ & $<10$ & 2005 & Endo TS & + & $0 \cdot 05$ & $0 \cdot 07$ & $\mathrm{R}$ \\
\hline $8, f, 22$ & $<10$ & Endo TS & - & $\mathrm{F}$ & 38 & $\mathrm{~K}$ & $<10$ & 2006 & Endo TS & - & 0.59 & $0 \cdot 50$ & $\mathrm{~F}$ \\
\hline $9, \mathrm{~m}, 27$ & $<10$ & Endo TS & + & $\mathrm{R}$ & 53 & - & 22 , in & 2006 & Endo TS & + & $0 \cdot 15$ & $0 \cdot 04$ & $\mathrm{R}$ \\
\hline $10, f, 40$ & 35 & Endo TS & - & $\mathrm{R}$ & 41 & - & $<10$ & 2006 & Endo TS & + & 0.02 & $0 \cdot 03$ & $\mathrm{R}$ \\
\hline $11, \mathrm{~m}, 56$ & $<10$ & TS & + & $\mathrm{R}$ & 124 & - & $<10$ & 2006 & Endo TS & + & $0 \cdot 21$ & 0.02 & $\mathrm{R}$ \\
\hline $12, f, 27$ & - & Endo TS & - & $\mathrm{F}$ & 2 & $\mathrm{~K}$ & $<10$ & 2006 & Endo TS & - & $0 \cdot 01$ & - & $\mathrm{R}$ \\
\hline $13, \mathrm{f}, 54$ & - & Endo TS & - & $\mathrm{R}$ & 32 & - & - & 2006 & Endo TS & - & $0 \cdot 02$ & - & $\mathrm{R}$ \\
\hline $14, f, 31$ & $<10$ & TS & - & $\mathrm{R}$ & 104 & - & $<10$ & 2007 & Endo TS & + & $0 \cdot 01$ & - & $\mathrm{R}$ \\
\hline
\end{tabular}

Age, age at second surgery; $\mathrm{f}$, female; $\mathrm{m}$, male; MRI, magnetic resonance imaging results given as maximal diameter of the visualized adenoma in mm; MRI*, computed tomography scan was made instead of an MRI scan; MRI - , no adenoma identified; MRI in, invasion in cavernous sinus or other parasellar structures; TE, transethmoidal pituitary surgery; TS, microscopic transsphenoidal pituitary surgery; Endo TS, endoscopic transsphenoidal pituitary surgery; Histology + , evidence of ACTH producing adenoma on histological examination; Histology -, no evidence of ACTH producing adenoma on histological examination; Histology NT, no tissue obtained during surgery; CLA, preoperative therapy with cortisol lowering agents; M, metyrapone; K, ketoconazole; Cortisol basal, fasting plasma cortisol level at $0800 \mathrm{~h}$ on seventh day after surgery; dex, plasma cortisol level at $0800 \mathrm{~h}$ after $1 \mathrm{mg}$ dexamethasone overnight; R, remission; F, failure.

will invariably result in recurrence of $\mathrm{CD}$ and all available medicaments have significant side-effects. ${ }^{18}$

Repeated TS may be a good treatment option for persistent or recurrent $\mathrm{CD}$. It has the potential to instantly cure $\mathrm{CD}$, while adrenal and pituitary function may remain intact. However, few investigators have addressed the results of repeated TS and the reported risk of hypopituitarism and other complications is higher than after the first TS. ${ }^{19-26}$ Furthermore all previous studies operated upon patients via the conventional microscopic technique of TS. Cappabianca et al. have suggested that the endoscopic technique of TS might be considered the procedure of choice in recurrent or residual pituitary adenomas, as the wider and direct visual control of the surgical field provides an advantage if the anatomy has been distorted by previous surgery. ${ }^{27}$ No results on repeated TS via the endoscopic technique in CD have been published till now. ${ }^{27,28}$

In order to gain insight into the role of repeated TS as a treatment option for persistent or recurrent $\mathrm{CD}$, we evaluated the remission rates and complications of repeated TS in 14 patients, treated in our hospital between 1999 and 2007. All patients were operated via the endoscopic technique.

\section{Patients and methods}

\section{Patients}

Between 1999 and 2007, 68 endoscopic TS were carried out for CD in our hospital. Fourteen of these operations were repeated TS, for persistent $C D$ in six patients and recurrent $C D$ in eight patients. The medical records of these patients were retrospectively reviewed. There were five males and nine females and age at time of the second surgery was $37 \cdot 2 \pm 10 \cdot 3$ years (Table 1 ).

Between 1999 and 2007 a total of 24 patients were treated for persistent or recurrent CD. Besides the 14 patients who underwent endoscopic repeated TS, 5 patients underwent conventional pituitary radiotherapy, 4 patients underwent stereotactic radiosurgery and 1 patient underwent a bilateral adrenalectomy. A multidisciplinary team of neurosurgeons, endocrinologists and a radiotherapist decided which therapy for persistent or recurrent CD was the optimal therapy for each individual patient, taking into account the invasiveness of the adenoma, findings at previous surgery, the physical condition of the patient and the patient's preference.

\section{Diagnostic evaluation before the first and second TS}

The initial diagnosis of hypercortisolism was based on clinical symptoms and biochemical tests, including 24-h urinary free cortisol measurements, assessment of the plasma cortisol and ACTH circadian rhythm and an overnight low dose dexamethasone suppression test $(1 \mathrm{mg}$ at $11 \mathrm{pm}) .{ }^{29} \mathrm{~A}$ CRH-test $(100 \mu \mathrm{g} \text { human } \mathrm{CRH} \text { i.v. })^{30}$ and a high-dose dexamethasone suppression test ${ }^{31}$ was performed in most patients. In addition pituitary imaging by contrast enhanced magnetic resonance imaging (MRI) was performed in all patients, except in one patient where contrast enhanced computed tomography 
(CT) scanning was used, to search for a pituitary adenoma. Eight patients underwent bilateral inferior petrosal sinus sampling with i.v. stimulation with $100 \mu \mathrm{g}$ human $\mathrm{CRH}$, which confirmed the pituitary origin of hypercortisolism in all eight patients. ${ }^{32}$

To document the persistence of hypercortisolism after TS or relapse of hypercortisolism in patients who were in remission for some time after TS, 24-h urinary free cortisol was measured, an overnight $1 \mathrm{mg}$ dexamethasone suppression test was performed, and midnight plasma cortisol was assessed. A new MRI scan was performed before the second TS in all patients.

\section{Surgical procedures}

All repeated pituitary operations in this series were performed via an endoscopic binostril endonasal transsphenoidal technique. This technique was introduced in our hospital in 1994, and first used for CD in 1997. From 1998 onward practically all TS were performed endoscopically. The surgeries were exclusively performed by two neurosurgeons. The technique is very similar to the technique that Jho et al. and Cappabianca et al. have described previously. ${ }^{33-36}$ However, a binostril, transsphenoidal, endoscopic approach to the sella turcica during which the endoscope is handheld was used.

For endoscopic transnasal TS $0^{\circ}$ and $30^{\circ}$ rigid endoscopes with a lens diameter of $4 \mathrm{~mm}$ with a separate shaft were used, which allow easy and comfortable holding, while offering a suction-irrigationsystem for cleaning the lens (Karl Storz GmbH, Tuttlingen, Germany). The instruments used are principally the same as with the microsurgical technique. The technique of repeated surgery is in no way different from primary surgery. In two recent cases electromagnetic neuronavigation was used for orientation and localization of a very small tumour.

In patients with recurrent $\mathrm{CD}$ a selective adenomectomy was performed if MRI identified the tumour. In case of negative MRI investigations a hemihypophysectomy was performed based on intra-operative findings. In patients with persistent CD after first TS, a total hypophysectomy was performed during repeated TS. Although this term suggests complete removal of all contents of the sella, it is never the intention to remove all pituitary tissue. Total hypophysectomy indicates the surgical exploration of the complete contents of the sella and removal of all anterior pituitary tissue that might harbour adenoma tissue. As soon as this goal seems to be achieved further surgery is discontinued and thus pituitary tissue may be left in place.

\section{Perioperative treatment}

Cortisol lowering agents, metyrapone and/or ketoconazole, were given for a period of 4 months preoperatively in 9 patients before the first TS and in 7 patients before the second TS.

Administration of glucocorticoids i.v. (prednisolone, $25 \mathrm{mg}$ every $8 \mathrm{~h}$ ) was started one hour before surgery. After 2 days glucocorticoids were given orally and the dose was tapered rapidly. There was an interval of at least $48 \mathrm{~h}$ between the last dose of glucocorticoids and the first postoperative measurement of fasting plasma cortisol on the seventh day postoperatively.

\section{Postoperative evaluation after first and second TS}

On the seventh day postoperatively early biochemical evaluation was carried out, consisting of measurement of fasting ( $8 \mathrm{am})$ plasma cortisol. If it was lower than $200 \mathrm{nmol} / \mathrm{l}$ substitution therapy with hydrocortisone, $30 \mathrm{mg}$ a day, or cortisone acetate, $37.5 \mathrm{mg}$ daily, was prescribed. Patients were re-evaluated every $2-4$ weeks during the first 3 months after surgery and then at 2-3 months intervals during the first year. Thereafter they were evaluated at least once a year.

The fasting plasma cortisol concentration was measured at each visit. In addition an overnight $1 \mathrm{mg}$ dexamethasone suppression test was carried out in 1 and 3 months postoperatively, and thereafter in patients who were in remission once yearly or earlier in case of clinical suspicion of relapse. If a patient received glucocorticoid substitution postoperatively, the dose was reduced gradually and stopped, if possible, between 3 and 12 months after surgery. Thereafter the integrity of the hypothalamic-pituitary-adrenal axis was assessed by an insulin-hypoglycaemia test. ${ }^{37}$ The thyrotrophic, gonadotrophic and somatotrophic axis were checked regularly.

\section{Criteria for remission and relapse}

Remission was defined as disappearance of clinical symptoms of hypercortisolism with basal plasma cortisol level $\leq 50 \mathrm{nmol} / \mathrm{l}$ after glucocorticoid withdrawal for 24-48 h and/or suppression of plasma cortisol level $\leq 50 \mathrm{nmol} / \mathrm{l}$ after overnight $1 \mathrm{mg}$ dexamethasone within the first 3 months after surgery. ${ }^{6,7,10}$ Relapse was defined as development of clinical symptoms of hypercortisolism and inadequate suppression of plasma cortisol level after an overnight $1 \mathrm{mg}$ dexamethasone suppression test in patients who were in remission after the first surgery according to the previously mentioned criteria.

\section{Statistics}

Statistical analyses were performed using Pearson's $\chi^{2}$-tests $(\mathrm{P})$ and Wilcoxon's two sample tests $\left(\mathrm{P}^{\star}\right)$. Statistical significance was defined as $P<0.05$ (two tailed).

\section{Results}

\section{Remission rates after repeated TS (Fig. 1)}

The individual clinical data of the 14 patients are shown in Tables 1 and 2 . The mean interval between the first and the second TS was 59 months (median 39, range 2-185).

After repeated TS remission was achieved in 10 patients. Nevertheless, patients 1 and 9 received additional therapy. Patient 1 was concerned that hypercortisolism would recur and asked for additional radiotherapy. Patient 9 was the only patient with an invasive macro-adenoma that could not entirely be removed during the second surgery. Therefore the patient received additional gamma knife surgery although he was clinically and biochemically in remission.

None of the patients who were in remission after the second TS had a relapse during follow-up of mean 34 months (median 24, 


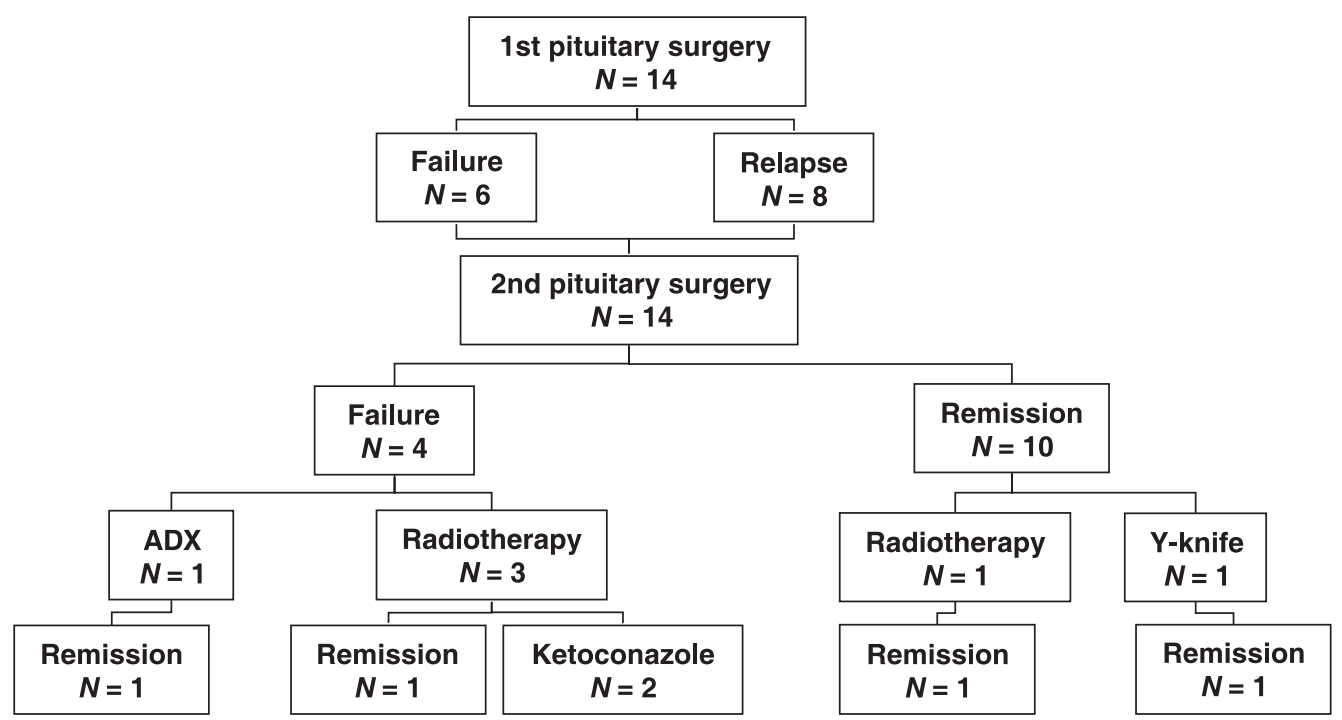

Fig. 1 Results of repeated transsphenoidal pituitary surgery via the endoscopic technique in patients with persistent of recurrent Cushing's disease (19992007). ADX, bilateral adrenalectomy.

Table 2. Substitution therapy and follow-up after second pituitary surgery (1999-2007)

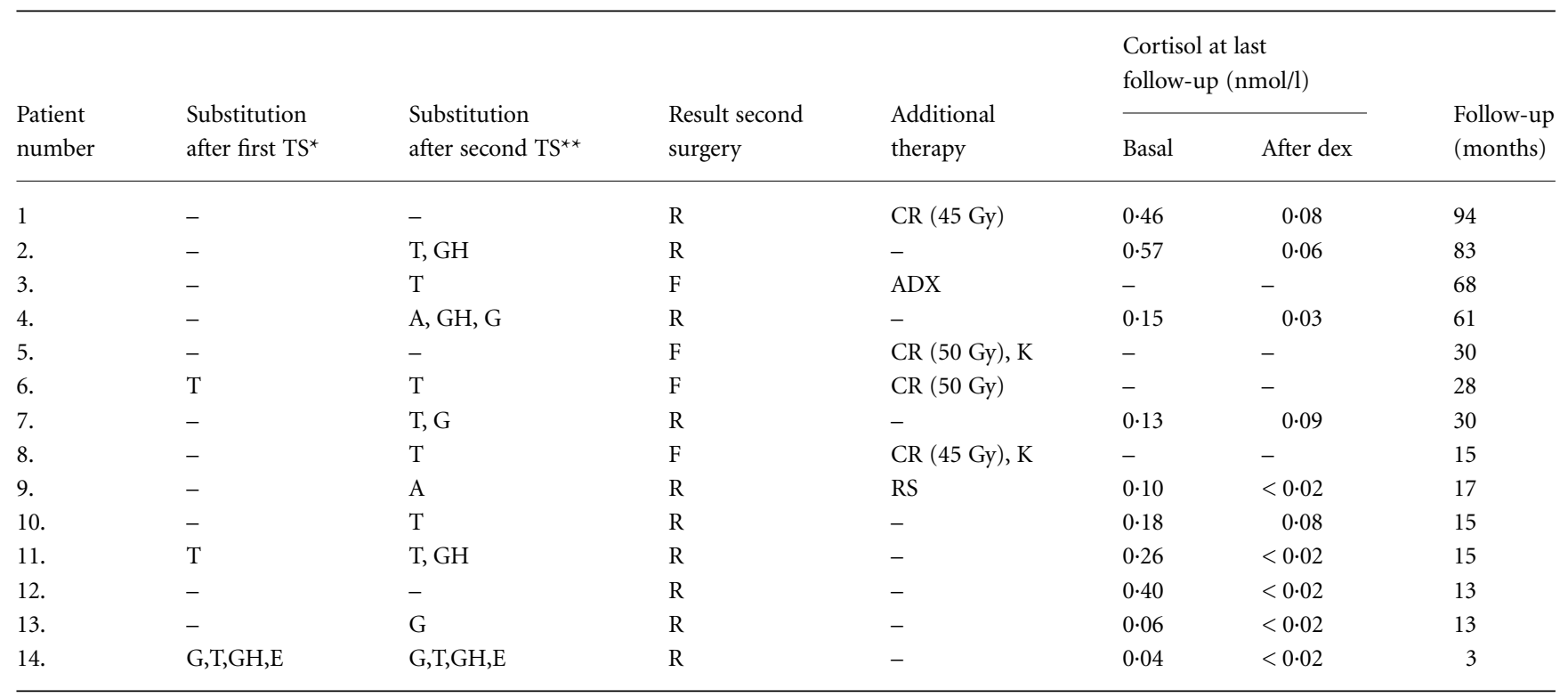

*At last evaluation before relapse was diagnosed or in case of persistent Cushing’s disease immidiately before second TS; ${ }^{* *}$, At last follow-up; A, androgens; D, desmopressin; E, estrogens; G, glucocorticoids; GH, growth hormone; T, levothyroxine; CR, conventional radiotherapy; RS, radiosurgery; ADX, bilateral adrenalectomy; K, ketoconazole; Cortisol at last follow-up, fasting plasma cortisol level at $0800 \mathrm{~h}$ and plasma cortisol level at $0800 \mathrm{~h}$ after $1 \mathrm{mg}$ dexamethasone overnight, measured in January 2008 in patients who are clinically in remission after 2 nd surgery.

range 4-97). At last follow-up plasma cortisol was not suppressed to $\leq 50 \mathrm{nmol} / \mathrm{l}$ after $1 \mathrm{mg}$ dexamethasone overnight in patients 1,2 , 7 and 10 (Table 2), but they had no clinical symptoms of hypercortisolism and 24-h urinary free cortisol excretion was not elevated. Four patients had persistent CD after the second TS. Patient 3 underwent a bilateral adrenalectomy and patients 5, 6 and 8 received conventional radiotherapy.

There were no statistically significant differences between the patients who underwent successful or unsuccessful repeated TS with respect to the following parameters: visualization of an adenoma on
MRI before first or second TS, histopathological confirmation of an ACTH secreting adenoma after first or second TS, treatment with cortisol lowering agents before first or second TS, the operation technique used during the first TS, persistent $v s$. recurrent disease after the first TS, age, gender and interval between the two TS.

\section{Complications of repeated TS}

Six of the 14 patients had mild transient diabetes insipidus. Six patients had cerebrospinal fluid (CSF) leakage, 4 intra-operatively 
Table 3. Overview of previously published results of repeated TS in patients with persistent or recurrent CD

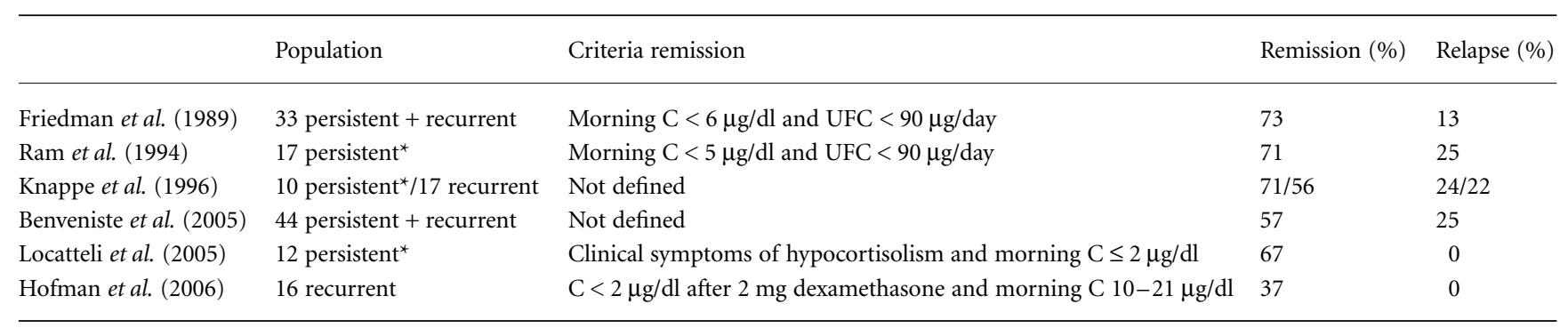

TS, transsphenoidal pituitary surgery; CD, Cushing's disease; ${ }^{*}$, immediate reoperation; C, plasma cortisol; UFC, urinary free cortisol excretion.

(closed with a fat graft) and 2 postoperatively. All six patients with CSF leakage were treated successfully with an external lumbar drain. Two patients required a reoperation to close the leak. More serious complications occurred in two patients. Patient 5 had blood loss from the right cavernous sinus during second TS. Damage of the internal carotid artery was excluded via an angiogram. Surgery was terminated before any tissue was removed and a tampon was placed that was removed via reexploration 1 week later. A few hours after the reexploration the patient developed a hemiparesis, due to occlusion of the left internal carotid artery just above the bifurcation. This was very unlikely a direct complication of the TS because the site of occlusion of the internal carotid artery was lower than the operation area. Although the patient improved significantly during the revalidation process, permanent disabilities remain. Patient 11 had postoperative bleeding from the sphenopalatine artery. Reexploration was required with successful coagulation of the artery. The patient recovered within a few days without other complications.

Only three patients required hormonal substitution after the first TS. After the second TS 11 patients required long-term hormonal substitution (Table 2). Of all patients, 8 required levothyroxine, 4 glucocorticoids, $4 \mathrm{GH}$ and 2 androgens and one oestrogens after repeated TS.

\section{Discussion}

The present study is the first study to report on the outcome of repeated TS via the endoscopic technique in patients with persistent or recurrent CD. In 1994 the endoscopic technique for TS was introduced in our hospital. Because of the minimal invasiveness, the excellent view of the surgical field and wider working angle, practically all TS were done endoscopically from 1998 onward. Before the introduction of the endoscopic technique we regarded repeated TS as a technically difficult procedure. Therefore, most patients with persistent and recurrent CD treated in our centre before 1999 underwent bilateral adrenalectomy or radiotherapy, and only four patients underwent repeated TS. Only one of these four patients was cured. After the introduction of the endoscopic technique repeated TS became more feasible. The wider view of the endoscopic technique provides an advantage, during repeated TS, as the anatomy is altered due to the previous operation. ${ }^{27}$ A substantially higher remission rate of $71 \%$ was achieved in the 14 patients operated on endoscopically and there was no relapse during followup of median 24 months.
The remission rate of $71 \%$ achieved in this study compares favourably with the remission rates previously reported after repeated TS via the conventional microscopic technique, which vary between $37 \%$ and $73 \%$, with a $0-25 \%$ relapse rate ${ }^{19-24}$ (Table 3 ). When comparing the reported remission rates, it is important to note that the studies were carried out in different patient groups. Three studies included patients with both persistent and recurrent $\mathrm{CD},{ }^{19-21}$ whereas other studies reported on patients with either persistent ${ }^{22,23}$ or recurrent ${ }^{24} \mathrm{CD}$. Criteria for remission also differed. In three studies immediate repeated TS was performed in case of persistent $\mathrm{CD}^{21-23}$ However, this strategy ignores the fact that some patients who do not have a low early postoperative basal plasma cortisol level do achieve remission, so by using this strategy some patients will unnecessarily undergo immediate repeated TS. ${ }^{8}$ Overall, the remission rates reported after second TS in persistent or recurrent $\mathrm{CD}$ seem to be slightly lower than the remission rates reported after first TS which vary from $50 \%$ to $90 \%$, but are mostly $70-85 \%{ }^{3-9}$ Nevertheless, the majority of the patients with persistent or recurrent CD can still instantly be cured by repeated TS, and the remission rate we achieved via the endoscopic technique seems to be at least as good as the remission rate achieved by repeated TS via the conventional microscopic technique.

In this study $57 \%$ of the patients had a perioperative complication of the repeated TS. Although most complications in our series were mild and transient more serious complications occurred in two patients: one patient had a cerebrovascular accident postoperatively and another patient had postoperative bleeding from the sphenopalatine artery. The latter complication is not a rare complication of microscopic TS, occurring in $3.4 \%$ of all cases. Vascular complications of endoscopic TS and microscopic TS are identical. ${ }^{38}$ We previously reported a complication rate of $29 \%$ in our study on results of primary endoscopic TS in patients with $\mathrm{CD},{ }^{3}$ which is similar to the complication rates reported in studies of primary microscopic TS in patients with CD. The studies on repeated TS in patients with persistent or recurrent $\mathrm{CD}$ report complication rates varying between $0 \%$ and $91 \% .{ }^{19-24}$ Although complication rates are influenced substantially by differences in definitions, the complication rate of repeated TS seems to be higher than the complication rate of primary TS.

Especially CSF leakage has been reported to occur more frequently during repeated TS than during the first TS, probably because of postoperative changes such as scar tissue but also as a result of a more aggressive surgical procedure in a usually small sella with a concave 
diaphragm. ${ }^{22,28,39} \mathrm{CSF}$ leakage occurred in $43 \%$ of the patients in this study, intra-operatively in four patients and postoperatively in two patients. Previously, we reported a CSF leakage rate of $8.5 \%$ in primary endoscopic TS in patients with CD operated on by the same neurosurgeons that operated the patients in this study. ${ }^{3}$ When comparing rates of CSF leakage it is important to note that most studies only report on the rates of postoperative CSF leakage. The rate of postoperative CSF leakage is lower (1-4\% during first TS) than the rate of intra-operative CSF leakage (9-25\% during first TS). ${ }^{39,40}$ Because intra-operative CSF leakage, which is usually not regarded as a complication, also occurs frequently during the first TS and the risk of meningitis is minimal if patients are given a lumbar drain, ${ }^{41}$ we believe that the higher chance of CSF-leakage during repeated TS should not be a reason to refrain from repeated TS.

The chance of hypopituitarism after repeated TS is higher than after the first TS. Reported percentages of hormonal deficiencies in patients with CD after the first TS vary from $2 \%$ to $48 \%$, but are mostly around $20 \%$. Ram et al. ${ }^{23}$ and Friedman et al..$^{20}$ reported rates of hormonal deficiencies after repeated TS in $41 \%$ and $50 \%$ of the patients. Locatelli et al. found an extremely high rate of hormonal deficiencies (100\%), but all patients underwent a total hypophysectomy. ${ }^{22}$ Hofmann et al. ${ }^{24}$ and Knappe et al. ${ }^{21}$ report on new hormonal deficiencies in $0 \%$ and $8 \%$. In the present series the percentage of patients with hormonal deficiencies was $78 \%$ after the second TS, with six patients having only one hormonal deficiency. The rate of hormonal deficiencies was $48 \%$ in our earlier study on results of first endoscopic TS in patients with $\mathrm{CD} .{ }^{3}$ The higher rates of hypopituitarism after repeated TS compared to after the first TS can be expected because additional pituitary tissue is removed. Even so, the risk of hypopituitarism after second TS seems to be lower than reported rates of hypopituitarism several years after radiotherapy. ${ }^{9,11}$

The success rate of repeated TS for persistent or recurrent CD depends on the correct selection of patients. In our opinion TS is a good treatment option if there is a reasonable chance that it will be successful. CD can be controlled instantly with the possibility to normalize cortisol circadian rhythm and keep the pituitary adrenal axis intact. Radiotherapy, however, is a good option if an adenoma is invasive.

Success rates of TS also critically depend on the skills and the experience of the neurosurgeons. ${ }^{42}$ Repeated TS is an even more difficult procedure than a first TS and repeated TS is infrequently performed. Thus it is advised to concentrate repeated TS for CD in a limited number of specialized centres.

In conclusion, repeated transsphenoidal pituitary surgery (TS) is a good therapeutic option for selected patients with persistent or recurrent Cushing's disease $(\mathrm{CD})$, with the potential to achieve remission in the majority of patients. The remission rate of $71 \%$ we achieved via the endoscopic technique of repeated TS compares favourably with the remission rate of repeated TS via the conventional microscopic technique previously described in the literature. The excellent view of the surgical field during endoscopic TS provides an advantage in case of altered anatomy due to previous surgery. However, only a randomized trial can definitively assess whether the endoscopic or the microscopic technique of TS is the preferred technique for repeated surgery in patients with persistent or recurrent CD.

\section{References}

1 Arnaldi, G., Angeli, A., Atkinson, A.B. et al. (2003) Diagnosis and complications of Cushing's syndrome: a consensus statement. Journal of Clinical Endocrinology and Metabolism, 88, 5593-5602.

2 De Martin, M., Giraldi, F.P. \& Cavagnini, F. (2006) Cushing's disease. Pituitary, 9, 279-287.

3 Netea-Maier, R.T., van Lindert, E.J., den Heijer, M. et al. (2006) Transsphenoidal pituitary surgery via the endoscopic technique: results in 35 consecutive patients with Cushing's disease. European Journal of Endocrinology, 154, 675-684.

4 Shimon, I., Ram, Z., Cohen, Z.R. et al. (2002) Transsphenoidal surgery for Cushing's disease: endocrinological follow-up monitoring of 82 patients. Neurosurgery, 51, 57-61.

5 Kelly, D.F. (2007) Transsphenoidal surgery for Cushing's disease: a review of success rates, remission predictors, management of failed surgery, and Nelson's Syndrome. Neurosurgical Focus, 23, E5.

6 Atkinson, A.B., Kennedy, A., Wiggam, M.I. et al. (2005) Long-term remission rates after pituitary surgery for Cushing's disease: the need for long-term surveillance. Clinical Endocrinology, 63, 549559.

7 Rees, D.A., Hanna, F.W., Davies, J.S. et al. (2002) Long-term followup results of transsphenoidal surgery for Cushing's disease in a single centre using strict criteria for remission. Clinical Endocrinology, 56, 541-551.

8 Pereira, A.M., van Aken, M.O., van Dulken, H. et al. (2003) Longterm predictive value of postsurgical cortisol concentrations for cure and risk of recurrence in Cushing's disease. Journal of Clinical Endocrinology and Metabolism, 88, 5858-5864.

9 Liu, J.K., Fleseriu, M., Delashaw, J.B. Jr et al. (2007) Treatment options for Cushing disease after unsuccessful transsphenoidal surgery. Neurosurgical Focus, 23, E8.

10 Biller, B.M., Grossman, A.B., Stewart, P.M. et al. (2008) Treatment of ACTH-dependent Cushing's syndrome: a consensus statement. Journal of Clinical Endocrinology and Metabolism.

11 Minniti, G., Osti, M., Jaffrain-Rea, M.L. et al. (2007) Long-term follow-up results of postoperative radiation therapy for Cushing's disease. Journal of Neuro-Oncology, 84, 79-84.

12 Sheehan, J.P., Niranjan, A., Sheehan, J.M. et al. (2005) Stereotactic radiosurgery for pituitary adenomas: an intermediate review of its safety, efficacy, and role in the neurosurgical treatment armamentarium. Journal of Neurosurgery, 102, 678-691.

13 Favia, G., Boscaro, M., Lumachi, F. et al. (1994) Role of bilateral adrenalectomy in Cushing's disease. World Journal of Surgery, 18, 462-466.

14 van Heerden, J.A., Young, W.F., Grant, C.S. et al. (1995) Adrenal surgery for hypercortisolism: surgical aspects. Surgery, 117, 466-472.

15 Gil-Cardenas, A., Cordon, C., Gamino, R. et al. (2007) Laparoscopic adrenalectomy: lessons learned from an initial series of 100 patients. Surgical Endoscopy, 4, 991-994.

16 Pereira, M.A., Halpern, A., Salgado, L.R. et al. (1998) A study of patients with Nelson's syndrome. Clinical Endocrinology, 49, 533539.

17 Kemink, S.A., Grotenhuis, J.A., De Vries, J. et al. (2001) Management of Nelson's syndrome: observations in fifteen patients. Clinical Endocrinology, 54, 45-52.

18 Nieman, L.K. (2002) Medical therapy of Cushing's disease. Pituitary, 5, 77-82.

19 Benveniste, R.J., King, W.A., Walsh, J. et al. (2005) Repeated transsphenoidal surgery to treat recurrent or residual pituitary adenoma. Journal of Neurosurgery, 102, 1004-1012. 
20 Friedman, R.B., Oldfield, E.H., Nieman, L.K. et al. (1989) Repeat transsphenoidal surgery for Cushing's disease. Journal of Neurosurgery, 71, 520-527.

21 Knappe, U.J. \& Ludecke, D.K. (1996) Persistent and recurrent hypercortisolism after transsphenoidal surgery for Cushing's disease. Acta Neurochirurgica Supplementum, 65, 31-34.

22 Locatelli, M., Vance, M.L. \& Laws, E.R. (2005) Clinical review: the strategy of immediate reoperation for transsphenoidal surgery for Cushing's disease. Journal of Clinical Endocrinology and Metabolism, 90, 5478-5482.

23 Ram, Z., Nieman, L.K., Cutler, G.B. et al. (1994) Early repeat surgery for persistent Cushing's disease. Journal of Neurosurgery, 80, 37-45.

24 Hofmann, B.M., Hlavac, M., Kreutzer, J. et al. (2006) Surgical treatment of recurrent Cushing's disease. Neurosurgery, 58, 1108-1118.

25 Pouratian, N., Prevedello, D.M., Jagannathan, J. et al. (2007) Outcomes and management of patients with Cushing's disease without pathological confirmation of tumor resection after transsphenoidal surgery. Journal of Clinical Endocrinology and Metabolism, 92, 33833388.

26 Dickerman, R.D. \& Oldfield, E.H. (2002) Basis of persistent and recurrent Cushing disease: an analysis of findings at repeated pituitary surgery. Journal of Neurosurgery, 97, 1343-1349.

27 Cappabianca, P., Alfieri, A., Colao, A. et al. (2000) Endoscopic endonasal transsphenoidal surgery in recurrent and residual pituitary adenomas: technical note. Minimally Invasive Neurosurgery, 43, 3843.

28 Rudnik, A., Zawadzki, T., Galuszka-Ignasiak, B. et al. (2006) Endoscopic transsphenoidal treatment in recurrent and residual pituitary adenomas: first experience. Minimally Invasive Neurosurgery, 49, 1014.

29 Wood, P.J., Barth, J.H., Freedman, D.B. et al. (1997) Evidence for the low dose dexamethasone suppression test to screen for Cushing's syndrome: recommendations for a protocol for biochemistry laboratories. Annals of Clinical Biochemistry, 34, 222-229.

30 Newell-Price, J., Morris, D.G., Drake, W.M. et al. (2002) Optimal response criteria for the human $\mathrm{CRH}$ test in the differential diagnosis of ACTH-dependent Cushing's syndrome. Journal of Clinical Endocrinology and Metabolism, 87, 1640-1645.

31 Biemond, P., de Jong, F.H. \& Lamberts, S.W. (1990) Continuous dexamethasone infusion for seven hours in patients with the Cushing syndrome. A superior differential diagnostic test. Annals of Internal Medicine, 112, 738-742.

32 Oldfield, E.H., Doppman, J.L., Nieman, L.K. et al. (1991) Petrosal sinus sampling with and without corticotropin-releasing hormone for the differential diagnosis of Cushing's syndrome. New England Journal of Medicine, 325, 897-905.

33 Cappabianca, P., Alfieri, A. \& de Divitiis, E. (1998) Endoscopic endonasal transsphenoidal approach to the sella: towards functional endoscopic pituitary surgery (FEPS). Minimally Invasive Neurosurgery, 41, 66-73.

34 Cappabianca, P., Alfieri, A., Thermes, S. et al. (1999) Instruments for endoscopic endonasal transsphenoidal surgery. Neurosurgery, 45, 392-395.

35 Jho, H.D. \& Carrau, R.L. (1997) Endoscopic endonasal transsphenoidal surgery: experience with 50 patients. Journal of Neurosurgery, 87, 4451.

36 Jho, H.D. \& Alfieri, A. (2000) Endoscopic transsphenoidal pituitary surgery: various surgical techniques and recommended steps for procedural transition. British Journal of Neurosurgery, 14, 432-440.

37 Plumpton, F.S. \& Besser, G.M. (1969) The adrenocortical response to surgery and insulin-induced hypoglycaemia in corticosteroidtreated and normal subjects. British Journal of Surgery, 56, 216-219.

38 Cavallo, L.M., Briganti, F., Cappabianca, P. et al. (2004) Hemorrhagic vascular complications of endoscopic transsphenoidal surgery. Minimally Invasive Neurosurgery, 47, 145-150.

39 Nishioka, H., Haraoka, J. \& Ikeda, Y. (2005) Risk factors of cerebrospinal fluid rhinorrhea following transsphenoidal surgery. Acta Neurochirurgica (Wien), 147, 1163-1166.

40 Cappabianca, P., Cavallo, L.M., Esposito, F. et al. (2002) Sellar repair in endoscopic endonasal transsphenoidal surgery: results of 170 cases. Neurosurgery, 51, 1365-1371.

41 van Aken, M.O., de Feelders, R.A.M.S., van de Berge, J.H. et al. (2004) Cerebrospinal fluid leakage during transsphenoidal surgery: postoperative external lumbar drainage reduces the risk for meningitis. Pituitary, 7, 89-93.

42 Bates, P.R., Carson, M.N., Trainer, P.J. et al. (2008) Wide variation in surgical outcomes for acromegaly in the UK. Clinical Endocrinology, 68, 136-142. 